$\xi=$ 离

\title{
Evaluation of the toxic influence of vitamin $E$ (dl-alpha-tocopheryl acetate) and treatment with aqueous extracts of cinnamon or anise on lipid profile and liver functions of female wistar rats
}

\author{
Sabah A. E. Ibrahim *, Murwan K. Sabahelkhier \\ Department of Biochemistry and Molecular Biology, Faculty of Science and Technology, Al Neelain University, Sudan, Khartoum \\ *Corresponding author E-mail: selhaj08@gmail.com
}

\begin{abstract}
The toxic effects of vitamin $\mathrm{E}$ and its treatment with aqueous extracts of Cinnamon or anise on lipid profile and liver functions of female wistar rats were examined for six weeks during September 2016 at labs in al-Neelain University. 18 rats were divided into six groups: 1. negative control group (sunflower oil), 2. Positive control group and rest groups given $(1500 \mathrm{mg} / \mathrm{Kg} / \mathrm{BW} /$ day of Vitamin E). After two hours, the four treated groups received a low dose $(2.13 \mathrm{~g} / \mathrm{Kg})$ and a high dose $(3.20 \mathrm{~g} / \mathrm{Kg}) 20 \mathrm{~g} / \mathrm{Kg}$ from Cinnamon aqueous extract (CAE) and Anise aqueous extract (AAE). At the end rats were sacrificed then serum and liver tissues were analyzed. Vitamin E toxic dose had caused a significant increase in serum Triglycerides (TG), Alanine amino transferase (ALT) levels, while it decreased the levels of Highdensity lipoprotein (HDL), low-density lipoprotein (LDL), total cholesterol (TC) and Aspartate amino transferase (AST). All treatments decreased TG and ALT levels. CAE low dose significantly increased TC, LDL and HDL levels. CAE high dose caused a significant decrease in AST, TC, and LDL. Both doses of AAE, caused significant increases on AST levels, and only anise low dose caused a significant decrease on TC and LDL levels. Vitamin E toxic dose caused severe fatty change in liver histology, which was near normal in both doses of CAE with a small necrosis in a low dose. Only AAE low dose normalized the liver. To conclude Vitamin E oral administration with a dose of $(1500 \mathrm{mg} / \mathrm{Kg})$ induced liver injury with an elevation in ALT and TG levels, which was significantly ameliorated by both treatments. Cinnamon was better than anise in ameliorating the toxicity. Cinnamon high dose was better than Cinnamon low dose; in contrast anise low dose was better than Anise high dose.
\end{abstract}

Keywords: Vitamin E (Dl-Alpha-Tocopheryl Acetate); Cinnamon Aqueous Extract (CAE); Anise Aqueous Extract (AAE); Lipid Profile; Liver Enzymes, Liver Histology; Wistar Rats.

\section{Introduction}

Fat-soluble vitamins can contribute to toxicity more than water soluble vitamins, because they are able to accumulate in the body for long time (Elango et al. 2015). Vitamin E has relatively low toxicity compared to the other fat-soluble vitamins (pour et al., 2011). It has no toxic effect when uptake from the natural diet, but when consumed as a supplement and higher than the upper intake level $(1000 \mathrm{mg} / \mathrm{kg} \sim 1600 \mathrm{IU} / \mathrm{kg})$ per day can cause hypervitaminosis E (Hathcock\& Griffiths, 2014). Vitamin E capsules are given to patients with fat mal-absorption syndromes or genetic defects in the hepatic $\alpha$ - tocopherol transfers protein $(\alpha$-TTP) and in severe malnutrition (Lebold\&Traber 2014). However, it is also available in pharmacies without prescription and recently these capsules have been increasingly bought in Sudan, especially by Sudanese women for homemade skin lightening and hair caring. On one hand high dosages of vitamin E $(\sim 2000 \mathrm{IU} / \mathrm{Kg})$ has been used in the treatment of some central nervous system diseases (Vatassery et al. 1998). However, on the other hand, hypervitaminosis E studies in rats and chicks have shown deleterious effects such as inhibition of the platelet aggregation and causing hemorrhagic (Pour et al. 2011).
Moreover, Hypervitaminosis E was found to increase the all-cause mortality (Bjelakovic et al. 2014). Recently, it has prompted prostate cancer (Klein et al. 2011). Besides it caused hepatotoxicity and an increase in liver biomarkers (SCF 2003). Hypervitaminosis $\mathrm{E}$ effect of the lipid profile and liver enzymes hasn't been intensively studied recently. However, it was reported to increase liver enzymes (SCF 2003), triglyceride levels (TG), heavy density lipoprotein (HDL) levels and total cholesterol (TC) levels (Bendich\&Machlin 1988). Hypervitaminosis $\mathrm{E}$ is treated with immediately ceasing the supplement consuming or by consumption of vitamin K supplementation (Nichols et al. 1989). Moreover, Natural plants with lipid lowering effects could be used to reduce vitamin E toxicity since it is a fat-soluble vitamin. Regarding their lipid, lowering effects, Cinnamon and Anise has been used in this study, no studies were conducted to investigate these herbs to vitamin interactions.

Cinnamon (Cinnamomum cassia) locally known as Girfah is one of the most important spices used in Sudan and particularly for flavoring tea. It is the inner bark of plants from the genus Cinnamomum (Morgan et al. 2014). Studies have shown that it has anti-diabetic (Longe et al. 2015), antioxidant (Morgan et al. 2014), anticancer (Rao\&Gan 2014), anti-mcrobial activities (Rao\&Gan, 2014)., hepatoprotective effects (Eidi etal., 2012) and lipid lowering effects (Rao\&Gan 2014).Cinnamon was found to have hypoli- 
pidemic effects, on diabetic patients, (Gullapalli et al. 2013) and on rats fed on high-fat diet (Rahman et al. 2013). It has decreased TG, LDL-C, and TC and no significant effects on HDL levels. Pimpinellaanisum $L$. or anise locally known as Yanson is an annual grassy herb belonging to the family of Umbelliferae (Apiaceae) (Shojaii\&Fard 2012). It is not used as common as Cinnamon in Sudan. Anise plant is mainly important for its fruits (Aniseeds), which mainly consist of volatile oil (trans-anethole), fatty acids, carbohydrates, and proteins and minerals (Shojaii\&Fard 2012) Medicinally Anise was found to have; anti-parasitic, antifungal, anti-ulcer, antimicrobial (Shojaii\&Fard 2012) and hepato protective properties (El-said et al. 2015). Moreover, it was shown to have hypolipidemic effects on $\mathrm{CCl} 4$ induced liver toxicity (Aboelnaga 2015), it reduced the level of lipid profile except HDL-c levels. The present study was done to investigate the influ- ence of Cinnamon and Anise as lipid lowering agents on vitamin $\mathrm{E}$ toxicity and the impacts on lipid profile and liver functions.

\section{Materials and methods}

\subsection{Materials}

Vitamin E (alpha-tocopheryl acetate) capsules (plate 1) are gelatinous capsules produced from the united pharmaceutical Mfg. Co. Ltd/. Amman, Jordan, was purchased from Mohamed Saeed pharmacy(Plate 1), Cinnamon barks (plate 2) and Aniseed (plate 3 ), were bought from an open market (Soug Al-Gomoaa) in Khartoum-Sudan.

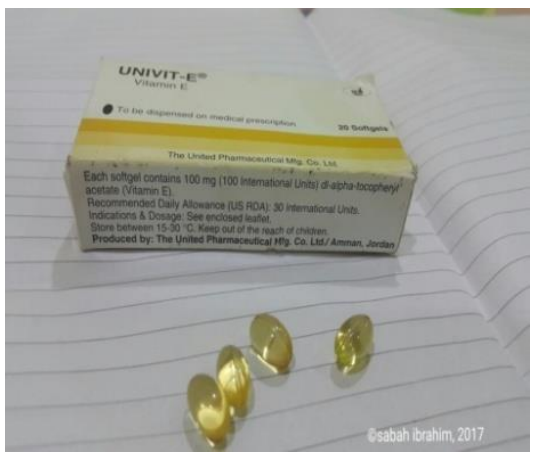

Plate. 1:Vitamin E (Dl-Alpha-Tocopheryl Acetate) Used in this Study and the Gelatinous Capsules

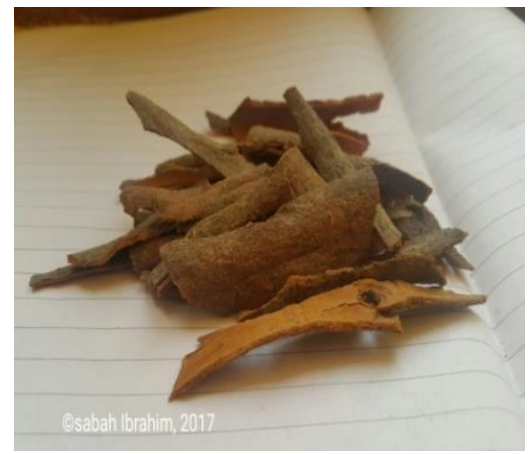

Plate. 2:The External Morphology of Cinnamon Barks Used in this Study

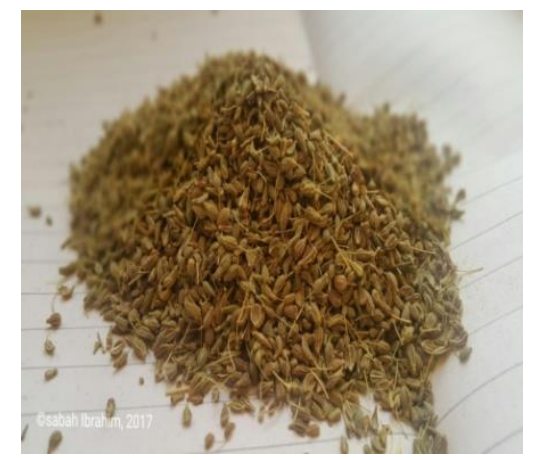

Plate. 3:The External Morphology of Aniseed Used in this Study

\subsection{Preparation of the materials}

\subsubsection{The vitamin $\mathbf{E}$ toxic dose preparation}

Capsules were cut, opened and taken with a sterile syringe carefully $(1500 \mathrm{mg} / \mathrm{Kg}$ per body weight per day $)$. Then they were dissolved in sunflower oil $(2 \mathrm{ml} / \mathrm{Kg} / \mathrm{bw}$ ) (as a vehicle) (De Bandt et al. 2002). The dose was then kept in dark bottles to avoid peroxidation, kept overnight and used in the next day immediately.

\subsubsection{Preparation of the plants aqueous extracts}

As described by Ismail (2014), the powder was produced from crushing the Cinnamon barks and the Aniseed using laboratory grinder. Then 200 grams powder of each plant were dissolved in $1000 \mathrm{ml}$ of water, boiled for 10 minutes, then were allowed to cool and filtered using a filter paper to obtain $20 \%$ aqueous extraction, the aqueous extract was prepared every two weeks.

\subsection{Design of the experiment}

\subsubsection{Experimental animals}

A group of 18 female rats of the Wistar strain (Rattusnorvegicus) bought from the faculty of pharmacy, university of Khartoum were used for this experiment. The animals were housed in cages at normal atmospheric temperature between 26 to $29^{\circ} \mathrm{C}$ and were given access to water and food (ad libitum) for three weeks adaptation period. The rats were then divided randomly into six groups (A, B, C, D, E and F); each consisting of three animals in different labeled cages with a mean weight of $75 \pm 5 \mathrm{~g}$.

\subsubsection{Experimental groups}

The rats were divided into six groups; the first group was the negative control group, which was given only sunflower oil (as a vehicle) with a dose of $2 \mathrm{ml} / \mathrm{Kg} / \mathrm{bw}$ (which was the minimum amount that could be given with a gavage syringe). The second group was the positive control group given a toxic dose of vitamin $\mathrm{E}(1500 \mathrm{mg} / \mathrm{Kg}$ per body weight per day). The rest groups were also given a toxic dose of vitamin $\mathrm{E}(1500 \mathrm{mg} / \mathrm{Kg} / \mathrm{bw} / \mathrm{day})$. Followed by two-hour administration of the treatments Cinnamon and Anise; the third group was given a low dose of Cinnamon aqueous extract (CAE) $(2.13 \mathrm{~g} / \mathrm{Kg}), 13 \mathrm{~g} / \mathrm{Kg})$, the fourth group give high dose of CAE $(3.20 \mathrm{~g} / \mathrm{Kg}), 20 \mathrm{~g} / \mathrm{Kg})$, the fifth group was given a low dose of Anise aqueous extract (AAE) $(2.13 \mathrm{~g} / \mathrm{Kg}) 13 \mathrm{~g} / \mathrm{Kg}$ and the sixth group was given a high dose of AAE $(3.20 \mathrm{~g} / \mathrm{Kg})$. The experiment was carried out for a period of six weeks.

\subsubsection{Biochemical parameters}

Lipid profile (TC, TG, HDL and LDL), liver enzymes (ALT\& AST) activities and liver histology were examined in this experiment.

\subsubsection{Blood collection and analysis}

At the end of the experiment rats were sacrificed to take the blood samples. Blood samples were collected in test tubes and allowed to coagulate at room temperature. It was then centrifuged at 3000 rpm for 30 minutes in a centrifuge machine. The clear non hemolysed supernatant serum was quickly removed and samples were immediately analyzed for liver enzymes (ALT and AST) and the rest of the samples were stored at $-20^{\circ} \mathrm{C}$ for lipid profile analysis. All biochemical parameters were measured by an enzymatic spectrophotometric method, using commercial kit (BioMed) and JENWAY 6305 spectrophotometer.

\subsubsection{Histological studies}

Livers were collected in clean, sterilized urine containers (from the autopsied rats), labeled, preserved in $10 \%$ formal saline immediately for fixation of the tissue. Then samples were taken in the histopathology laboratory in the faculty of the veterinary, university of Khartoum. The fixed tissues were then dehydrated with alcohol, and further embedded in paraffin, sectioned $(5 \mu \mathrm{m})$ with a rotary microtome and stained with hematoxylin, mounted with Canada's balsam. Slides were then investigated using a light microscope for any changes and (Eidi et al., 2012), steps were done by the aid of an automatic tissue processor. 


\subsubsection{Statistical analysis}

Statistical analysis was performed using the SPSS for Windows statistical package, version 16. Data were expressed as means \pm Standard error. The effects of drug treatments were evaluated statistically using the one-way analysis of variance (one-way ANOVA) followed by the LSD post-hoc test. Statistical significance was set at the $\mathrm{p}<0.05$ level.

\section{Results}

\subsection{Assessment of lipid profile}

\subsubsection{Assessment of triglycerides and high density lipoproteins}

Data of TG and HDL are presented on (Fig. 1). The diagram shows that vitamin $\mathrm{E}$ toxic dose $(1500 \mathrm{mg} / \mathrm{Kg} / \mathrm{BW} /$ day $)$ when given orally to female rats for six weeks caused a significant $(\mathrm{P}<$ $0.05)$ increase in triglycerides (TG) $(\mathrm{P}=0.007)$, while it significantly decreased the High-density lipoprotein (HDL) levels $(\mathrm{P}=0.009)$, when compared to the negative control group. All the treatment groups (Cinnamon and Anise) have significantly $(\mathrm{P}<0.05)$ decreased the ALT levels when compared to the positive control group. In correspondence to the positive control group, only rats treated with Cinnamon low dose has significantly $(\mathrm{P}=0.001)$ increased HDL levels with the rest treated groups showing no effects.

\subsubsection{Assessment of total cholesterol and low density lipopro-} tein

Data of total cholesterol and LDL are presented on (Fig. 2). The diagram shows that vitamin $\mathrm{E}$ toxic dose $(1500 \mathrm{mg} / \mathrm{Kg} / \mathrm{BW} /$ day $)$ when given orally to female rats for six weeks cause a significant $(\mathrm{P}<0.05)$ decrease in TC and LDL levels, when compared to the negative control group. Compared to the positive control group, CAE low dose significantly increase TC $(\mathrm{P}=0.007)$ and LDL levels $(\mathrm{P}=0.038)$. In contrast, $\mathrm{CAE}$ high dose significantly lower the total cholesterol levels $(\mathrm{P}=0.002)$ and the LDL levels $(\mathrm{P}=0.009)$ In addition AAE low dose significantly decline both the TC $(\mathrm{P}=0.023)$ and LDL levels $(\mathrm{P}=0.003)$, however AAE high dose caused no significant difference.

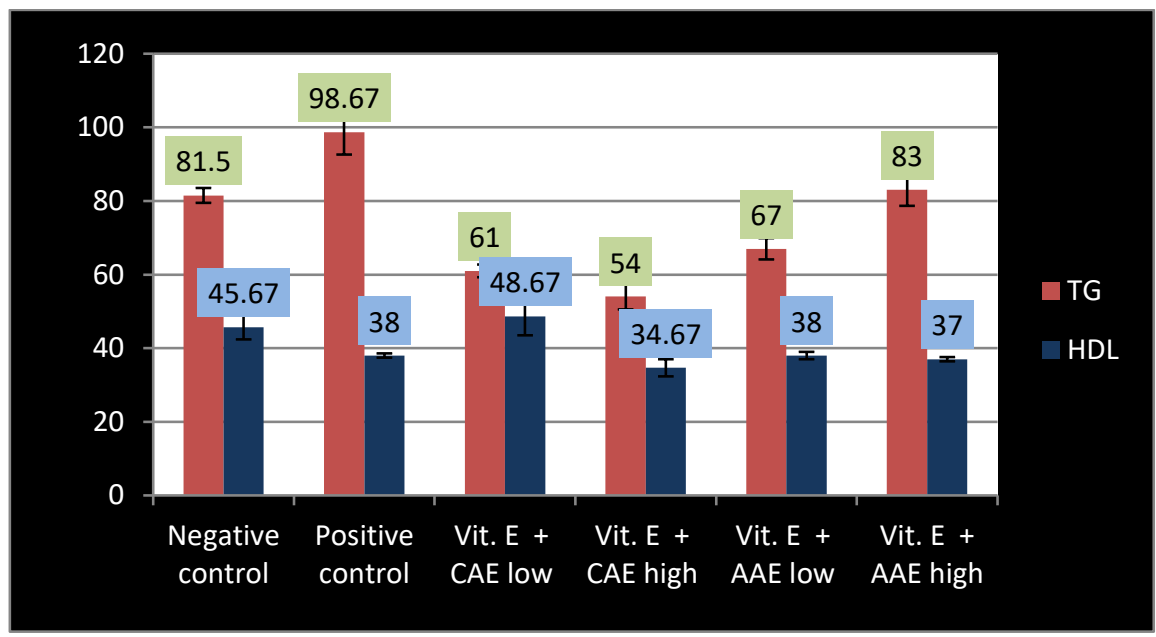

Fig. 1:The Effects of This Study on TG and HDL Levels. Values are given as Means \pm Standard Errors.

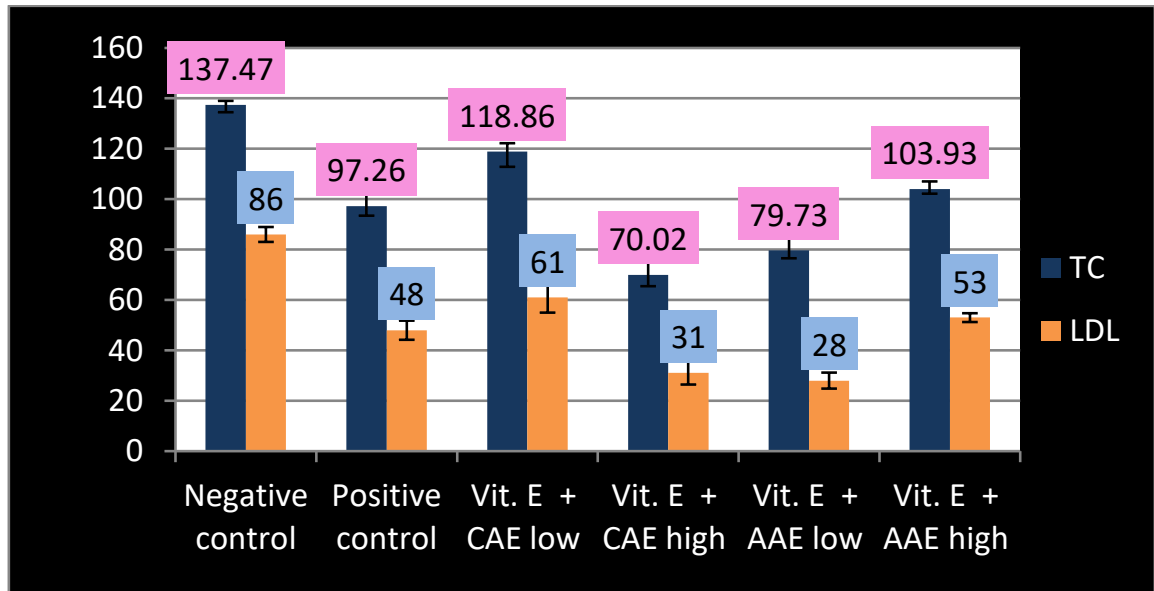

Fig. 2:The Effects of This Study on TC and LDL Levels. Values are given as Means \pm Standard Errors.

\subsection{Assessment of liver enzymes}

Data in (Fig. 3) shows that oral administration of vitamin E toxic dose $(1500 \mathrm{mg} / \mathrm{Kg})$ to female rats for six weeks induced a significant increase in $(\mathrm{P}=0.000)$ ALT levels, while it significantly decreased $(\mathrm{P}=0.001)$ AST levels when compared to the negative control group. All the treated groups had significantly $(\mathrm{P}<0.05)$ declined the ALT levels when compared with the positive control group; however Cinnamon was more effective than Anise. According to treatment with Cinnamon, only CAE high dose showed a significant lowering $(\mathrm{P}=0.000)$ of AST levels while CAE low dose caused no change.

On the other hand both doses of Anise have significantly increased the AST levels $(\mathrm{P}=0.012$ foe low dose and $\mathrm{P}=0.000$ for high dose) compared to the positive group. AST levels of rats treated with both doses of Cinnamon were significantly lower than those treated with Anise both doses. 


\subsection{Histological findings}

As shown in (Fig. 4) Liver histology of negative control group shows a slightly fatty change, while the positive control group indicates that vitamin $\mathrm{E}$ toxic dose caused a severe fatty change to rats' liver. CAE low dose has normalized the fatty change howev- er there was a necrosis, whereas cinnamon high dose completely normalized vitamin $\mathrm{E}$ toxic dose effect. On the other hand liver of rats treated with $\mathrm{AAE}$ decreased the toxicity however it was less than Cinnamon, and AAE high dose, failed to decrease the fatty change severity, resulting in more toxicity than the positive control group.

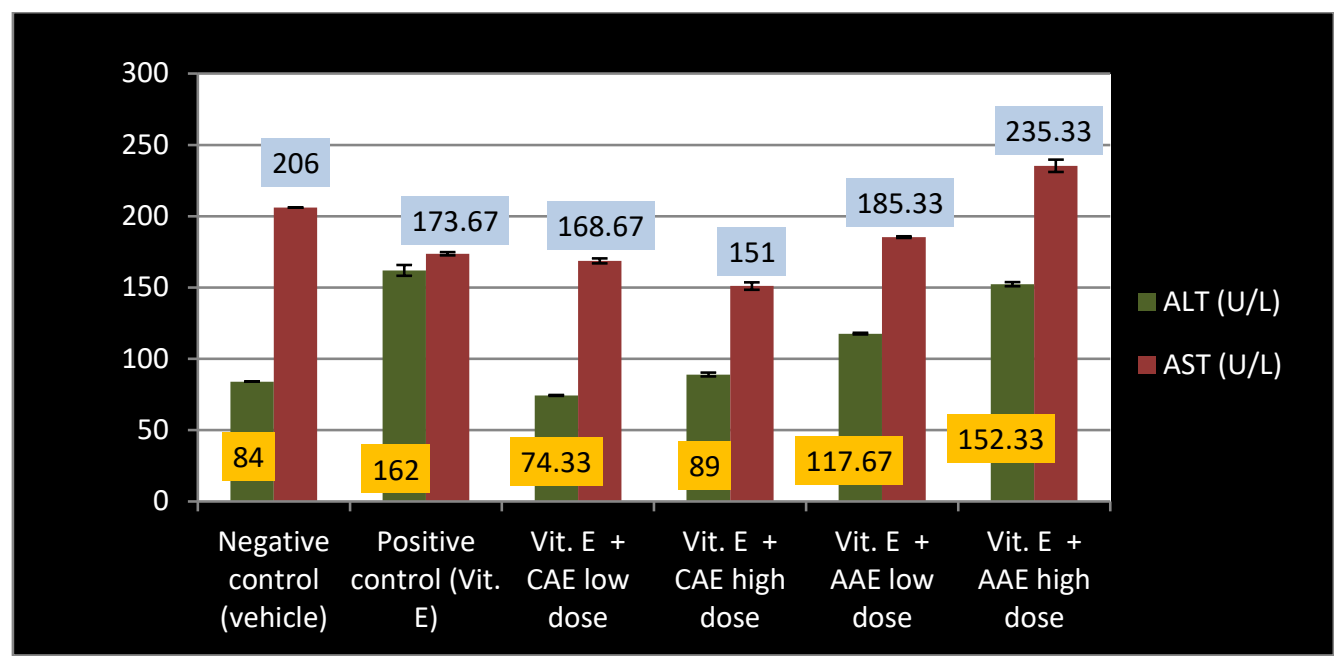

Fig. 3: Effects of Oral Treatment with Cinnamon or Anise on Liver Enzymes (ALT and AST) Levels of Female Wistar Rats Given Vitamin E Toxic Dose for Six Weeks.

(A)

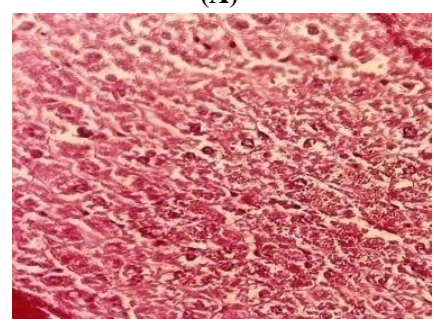

(C)

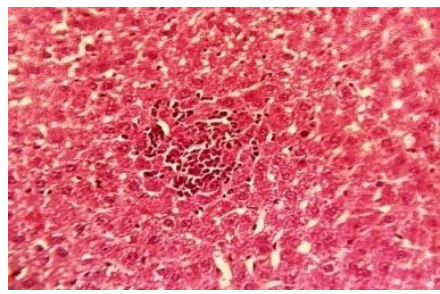

(E)

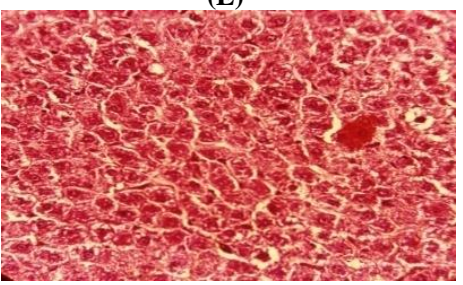

(B)

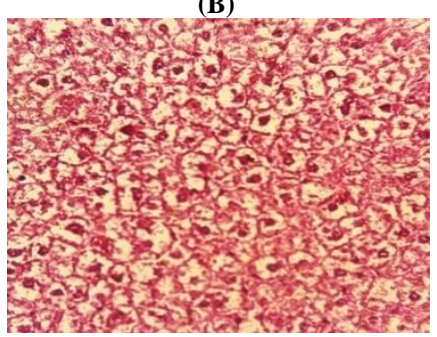

(D)

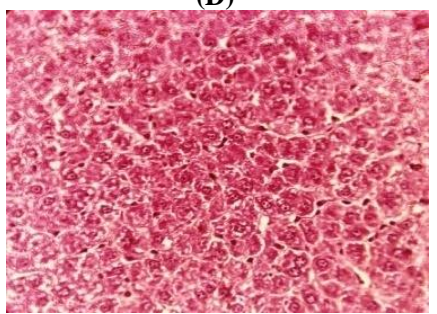

(F)

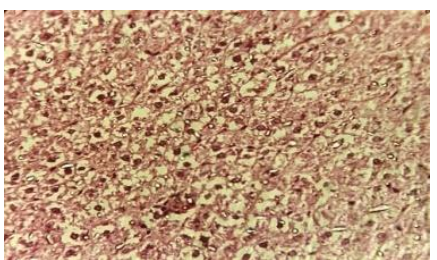

Fig. 4: The Impact of Vitamin E Toxic Dose and Treatment with Cinnamon or Anise on Liver Histology of Female Wistar Rats. (A) Liver Histology of the Negative Control Group Shows A Slightly Fatty Change, (B) Liver Histology of the Positive Control Group Indicates Severe Fatty Changes to Rats' Liver, (C) Liver Histology of Rats Treated with Cinnamon Low Dose. CAE Low Dose Has Decreased the Toxicity. However, there was A Necrosis, (D) Liver Histology of Rats Treated with Cinnamon High Dose. The toxicity was Improved Near Normality, (E) Liver Histology of Rats Treated with Anise Low Dose. It Indicates that the Toxicity Has Decreased But Less Than Cinnamon, and (F) Demonstrate Rats Treated with Anise High Dose, and It Has Failed to Decrease The Fatty Change Severity.

\section{Discussion}

The present study is the first study to investigate the effects of two different plants (Cinnamon and Anise), on vitamin E (dl-alpha tocopheryl acetate) toxicity on lipid profile and liver functions on female Wistar rats. Vitamin $\mathrm{E}$ is a fat-solublevitamin and a powerful antioxidant (Maya et al. 2012). Vitamin E toxicity can have deleterious effects in the liver since the vitamin is mainly metabo- lized there. Moreover, Cinnamon and Anise are lipid lowering agents who possess hepato protective and antioxidants effects that can help in reducing vitamin $\mathrm{E}$ toxicity.

Vitamin E toxicity effect on lipid profile was not studied recently, and very small information are present, it was reported to increase TG, HDL, LDL and cholesterol (Bendich and Machlin 1988). Moreover, since vitamin $\mathrm{E}$ is a fat-solublevitamin, the feeding of high fatty mixture diet was found to increase TG, TC and LDL but decreasing HDL levels (Rahman et al. 2013). 
The obtained result from the present study showed that vitamin E (dl-alpha-tocopheryl acetate) had increased the triglycerides levels while declining HDL, LDL and cholesterol of rats in contrast to the negative control group. These reductions are considered as ameliorative effects and not toxic. The duration of the present study and the toxic dose of vitamin $\mathrm{E}$ may not BE sufficient to cause deleterious effects on all lipids, and the utilization of vegetable oils (corn oil, hazelnut oil or peanut oil) as a vehicle for vitamin $\mathrm{E}$ were found to have harmful effects on the electrical activity of the heart (Ozdemir et al. 2003), and this was not considered in using sunflower oil as a vehicle.

Cinnamon high dose was more effective than Cinnamon low dose in dealing with vitamin $\mathrm{E}$ toxicity on lipid profile. On one hand both doses of Cinnamon have effectively reduced the increased levels of triglycerides made by vitamin E toxic dose. Similar findings were found in a study done to investigate hypocholesterolaemic activity on rats fed on a high mixed fat diet (Rahman et al. 2013).

On the other hand, Cinnamon low dose has increased TC, LDL and HDL levels, resulting in increasing the toxicity rather than declining it. Increasing HDL levels (good cholesterol) has been a result in many studies and was considered as an ameliorative effect (Ismail 2014 and Longe et al., 2015). However, the increasing in TC and LDL levels by Cinnamon low dose was not observed by any study yet, and this could be because vitamin $\mathrm{E}$ is a potent antioxidant, and this dose of Cinnamon was not sufficient to ameliorate its toxic effects.

Moreover, CAE high dose had no change on HDL levels however it reduced the levels of TC and LDL levels. This is similar to research done by Gullapalli et al. 2013 and Rahman et al., 2013.The polyphenolic compounds within Cinnamon function as reactive oxygen and nitrogen species scavengers, redox-active transition metal chelator and enzyme modulators resulting from an antioxidant activity (Morgan et al. 2014). Cinnamon can induce hepatic antioxidant enzymes activities, and thus it suppresses lipid peroxidation (Rahman et al., 2013), moreover, it can suppress the hepatic-3-hydroxyl- 3-methyl glutaryl Co-enzyme (HMG Co-A) reductase activity (which is a rate limiting enzyme in cholesterol synthesis) and thus reducing cholesterol (Ciftci et al. 2010).

Anise low dose was better than Anise high dose in dealing with vitamin $\mathrm{E}$ toxicity on lipid profile.On one hand, both doses of Anise had also decreased the increase of triglycerides levels made by vitamin $\mathrm{E}$ toxic dose, and both did not affect the HDL levels. On the other hand, only anise low dose significantly decreased the levels of Cholesterol and LDL while anise high dose showed no effect on them. Anise was observed to have hypolipidemic effects on $\mathrm{CCl}_{4}$-induced toxicity in rats (Aboelnaga 2015 \& El-Sayed et al. 2015), and type-2 diabetic rats (Rajeshwari et al., 2011). It was detected that anise reduced the level of cholesterol, triglycerides, LDL-c, VLDL-c, but increases the HDL-c levels. Anise extracts were found to have antioxidant activities in both linoleic acid and liposome model system suggesting that it could act as an antioxidant in diets containing fat (Al-Ismail \&Aburjai 2004). It was suggested that trans-anethole, might be responsible for the observed antioxidant properties (Singh et al., 2008). It also can chelate multivalent metal ions, which assist in lowering lipids (ElSayed et al. 2015).

Liver enzymes (ALT and AST) were used as biomarkers for liver injury. The effect of vitamin $\mathrm{E}$ toxic dose $(1500 \mathrm{mg} / \mathrm{Kg})$ has significantly increased the ALT levels indicating liver damage. This agrees with a study done to investigate the long term toxicity on vitamin $\mathrm{E}$ on rats (Wheldon et al. 1983). However, it significantly decreased AST levels. This is inconsistent with what was reported by (SCF 2003) in that the vitamin toxic dose has increased AST activity. As mentioned above vegetable oils found to affect the electrical activity of the heart (Ozdemir et al. 2003), this could contribute to the raising of AST levels in the negative control group, since AST is mostly concentrated on the heart.

The treatment of both doses of Cinnamon had normalized the levels of ALT and only CAE high dose has declined the AST levels with CAE low dose showing a non significant decrease. Cin- namon was similarly found to have hepatoprotective effects on $\mathrm{CCl}_{4}$ induced liver toxicity on rats Eidi et al. 2012 and diabetic rats Longe et al. 2015 by declining liver enzymes (such as ALT and AST). Some chemical constituents (polyphenols) of Cinnamon possess antioxidant activities that can scavenge free radicals (Morgan et al., 2014). Cinnamon was detected to increase superoxide dismutase and catalase enzymes levels' thus suggesting that an increase as the activity within the antioxidant-defense system, and an inhibition of lipid peroxidation are motives in the hepatoprotective activity (Eidi et al., 2012).

On the other hand, the present study indicates that both doses of anise coulddecrease the toxic effects of vitamin E on ALT. Studies on Anise were found to protect against liver damage triggered by $\mathrm{CCl}_{4}$ on rats (Aboelnaga, 2015 and El-Sayed et al., 2015) by reducing liver enzymes in crescent. Anises contain trans-anethole, which have antioxidant activity (Singh et al., 2008), thus it can protect against oxidative damage.

In addition, Anise treatments have caused an increase in AST levels resulting in more toxicity. This disagrees with many studies (Aboelnaga, 2015 and El-Sayed et al., 2015).

The liver histology of the negative control group showed slightly fatty change, but no necrosis was observed (fig 3-3-a).Vitamin $\mathrm{E}$ toxic dose $(1500 \mathrm{mg} / \mathrm{Kg})$ caused a severe fatty change in the liver (fig 3-3-b), but no necrosis was observed, limited hepatic damage and the occurrence of hepatic macrophage were observed in rats given high dosages of vitamin E for 104 weeks (Wheldon et al. 1983).

With an exception of a small necrosis in rats treated with CAE low dose; both Cinnamon doses have normalized the fatty change when compared to the positive control group. Similar results were showed in Liver histology of rats treated with cinnamon against $\mathrm{CCl}_{4}$ toxicity (Eidi et al., 2012). Anise low dose showed a normal liver.However, Anise high does show no difference from the positive control group. Cengiz et al. 2008 has found that there was no difference in the histopathology findings, and balloon degeneration was observed in both treated (anise) and untreated groups $\left(\mathrm{CCl}_{4}\right)$.

Some doses of both treatments showed negative effects. This may be because vitamin E, Cinnamon and Anise are powerful antioxidants, and in a study by Huang et al. 2002 it was found that the utilization of antioxidants combinations (vitamin $\mathrm{E}$ and $\mathrm{C}$ ), caused caused no benefit in lipid peroxidation reduction compared of using each antioxidant alone. Moreover, AAE high dose showed the highest toxicity. Anise was found to increase the levels of serum $\beta$ carotene, vitamin $\mathrm{A}, \mathrm{E}$ and $\mathrm{C}$ and some antioxidant enzymes in diabetic patients in a study done by Rajeshwari, et al. 2011 leading to more antioxidants (vitamin E and C), which which serves a benefit effect on that study. Suggesting that in this study, Anise raised the accumulation of antioxidants (including vitamin E) resulting in increasing amounts of vitamin $\mathrm{E}$ (thus toxicity)

\section{Conclusions}

A number of conclusions can be drawn from this experiment. Vitamin E toxic dose has affected the lipid profile by increasing TG and decreasing, Cholesterol, LDL and HDL levels. It has also caused liver injury raising ALT levels and causing severe fatty change to liver histology however it decreases AST levels, suggesting that the dose wasn't sufficient to cause deleterious effects on all parameters or commercial sunflower oil used as vehicle may have toxic effects on rats.

Both treatments have significantly a decrease TG and ALT levels, but cinnamon was more effective than Anise. Cinnamon was also better than Anise in treating the toxicity of vitamin E on AST levels.In treating the toxicity of vitamin $\mathrm{E}$ on $\mathrm{LDL}$ and $\mathrm{CHO}$ levels, Cinnamon high dose was better than Cinnamon low dose, in contrast anise low dose was better than Anise high dose. 


\section{References}

[1] Aboelnaga SMH. (2015). Effect of Some Levels of Cardamom, Clove and Anise on Hepatotoxicity in Rats Caused by CCL4 World Applied Sciences Journal, 33 (6): 854-865.

[2] Al-Ismail K M. \&Aburjai T. (2004). Antioxidant activity of water and alcohol extracts of chamomile flowers, Anise seeds and Dil seeds. Journal of the science of food and agriculture, 84 (2): 173178.https://doi.org/10.1002/jsfa.1625.

[3] Bendich A. \&Machlin L. J. (1988). Safety of oral intake of vitamin E.Am. J. Clin. Nutr. 48:612-619.

[4] Bjelakovic G., Nikolova D., and Gluud C. (2014). Antioxidant supplements and mortality. Current Opinion in Clinical Nutrition Metabolic Care, 17(1):40-4. [pubmed abstract]

[5] Cengiz N., Özbekb H., Himc A. (2008). Hepatoprotective Effects of Pimpinellaanisum Seed Extract in Rats. Pharmacologyonline, 3 : 870-874.

[6] Ciftci M., Simsek UG., Yuce A., Yilmaz O., and Dalkilic B. (2010). Effects of dietary antibiotic and Cinnamon oil supplementation on antioxidant enzyme activities, cholesterol levels and fatty acid compositions of serum and meat in Broiler Chickens. ActaVeterinaria Brno, 79(1): 33 40.https://doi.org/10.2754/avb201079010033.

[7] De Bandt M., Grossin M., Driss F., Pincemail J., Babin-Chevaye C., and Pasquier C. (2002). Vitamin E Uncouples Joint Destruction and Clinical Inflammation in a Transgenic Mouse Model of Rheumatoid Arthritis. Arthritis and rheumatism, 46 (2):522532.https://doi.org/10.1002/art.10085.

[8] Eidi A., Mortazavi P., Bazargan M., Zaringhalam J. (2012). Hepatoprotective activity of Cinnamon ethanolic extract against CCL4induced liver injury in Rats. EXCLI Journal, 11:495-507

[9] ElangoG., Venkataraman DD., Rao VS., and Kiran RVS. (2015). Hypervitaminosis. International Journal of Biomedical Research 6(3): 151-154.https://doi.org/10.7439/ijbr.v6i3.1735.

[10] El-Sayed MGA., Elkomy A., Samer S., and elbanna AH. (2015) Hepatoprotective effect of Pimpinellaanisum and Foeniculumvulgare against carbon tetrachloride induced fibrosis in Rats. World journal of pharmacy and pharmaceutical sciences, 4(6):78-88.

[12] GullapalliHS,Avinash P., TekadeNH, andGullapall I (2013). Effects of Consumption of Cinnamon on Blood Glucose and Lipid profile of the Patients of Type 2 Diabetes. Scholars Journal of Applied Medical Sciences (SJAMS), 1(2):28-32.

[13] Hathcock JN., and GriffithsJC. (2014). Vitamin and mineral safety. Council for Responsible Nutrition (CRN), Washington, D.C., $3^{\text {rd }}$ edition, 39-48.

[14] Huang HY,AppelLJ, Croft KD, Miller ER, Mori TA, and Puddey IB. (2002). Effects of vitamin $\mathrm{C}$ and vitamin $\mathrm{E}$ on in vivo lipid peroxidation: results of a randomized controlled trial. Am J ClinNutr, 76:549-55.

[15] Ismail NS, (2014). Protective effects of aqueous extracts of Cinnamon and Ginger Herbs against Obesity and diabetes in obese diabetic Rat. World Journal of Dairy \& Food Sciences, 9 (2): 145-153.

[16] Klein EA., Thompson IM., Tangen CM., Crowley JJ., Lucia MS. Goodman PJ., Minasian LM., Ford LG., Parnes HL., Gaziano JM., Karp DD., Lieber MM., Walther PJ., Klotz L., Parsons JK., Chin JL., Darke AK., Lippman SM., Goodman GE., Meyskens F L., and Baker L H. (2011). Vitamin E and the risk of prostate cancer: the Selenium and Vitamin E Cancer Prevention Trial (SELECT). JAMA, (14):1549-56. [Pubmedabstract].https://doi.org/10.1001/jama.2011.1437.

[17] LeboldM. and Traber O. (2014) Interactions between alphatocopherol polyunsaturated fatty acids and lipoxygenases during embryogenesis. Free RadicBiol Med., 66:116.https://doi.org/10.1016/j.freeradbiomed.2013.07.039.

[18] Longe AO., Momoh J., Adepoju PA. (2015). Effects of Cinnamon aqueous extract on blood glucose level, liver biomarker enzymes, heamatological and lipid profile parameters in alloxan-induced diabetic male albino Rats. European Scientific Journal, 1: 418-426

[19] Maya W., Mayur K., and Ashar S. (2012). Pharmaceutical Profile of Alpha-Tocopherol - A Brief Review. International journal of pharmaceutical and chemical sciences, 1 (3):1023-1039.

[20] Morgan AM., El-Ballal SS., El-Bialy BE, and EL-Borai NB. (2014). Studies on the potential protective effect of cinnamon against bisphenol A- and octylphenol-induced oxidative stress in male albino rats. Toxicology Reports, 1 (2014): $92-$ 101https://doi.org/10.1016/j.toxrep.2014.04.003.

[21] Nichols DK., Wolff MJ, Phillips LG., and Montali R.J. (1989). Coagulopathy in pink-backed pelicans pelecanusrefescens associated with hypervitaminosis E. Journal of zoo and wildlife medicine, 20:57-61.

[22] Ozdemir S., Ayaz M., Tuncer T., Ugur M., Turan B. (2003). Vegetable oils used as vitamin $\mathrm{E}$ vehicle affect the electrical activity of the Rat heart, Physiol. Res. 52: 767-771.

[23] Pour HA., Sis NM., Razlighi SN., Azar M.S., Babazadeh MH., Maddah MT., Reazei N., Namvari M.(2011). Effects of vitamin E on ruminant animal. Annals of Biological Research, 2 (4):244-251.

[24] Rahman S., Begum H., Rahman Z., Ara F., Iqbal MJ., and Yousuf AKM., (2013). Effect of cinnamon (Cinnamomum cassia) as a lipid lowering agent on hypercholesterolemic rats.Journal of Enam Medical College, 3(2):94-98.https://doi.org/10.3329/jemc.v3i2.16132.

[25] Rajeshwari U., Shobha I., and Andallu B. (2011). Comparison of aniseeds and coriander seeds for antidiabetic, hypolipidemic and antioxidant activities. Spatula DD., 1 (1): 916.https://doi.org/10.5455/spatula.20110106123144.

[26] Rao PV. andGan SH. (2014). Cinnamon: A Multifaceted Medicinal Plant. Evidence-Based Complementary and Alternative Medicine, 2014: 1-12https://doi.org/10.1155/2014/642942.

[27] SCF (2003). Opinion of the Scientific Committee on Food on the Tolerable Upper Intake Level of Vitamin E.European commission health \& consumer protection directorate-general Brussels - Belgium, 1-18.

[28] Shojaii A., and Fard, MA, (2012). Review of Pharmacological Properties and Chemical Constituents of Pimpinellaanisum. International Scholarly Research Network Pharmaceutics 2012: 1-8

[29] Singh G., Kapoor IPS., Singh P., de Heluani CS., and Catalan CAN. (2008). Chemical composition and antioxidant potential of essential oil and oleoresins from anise seeds (Pimpinellaanisum L.). International Journal of Essential Oil Therapeutics, 2(3):122-130.

[30] Vatassery GT., Fahn S., and Kuskowski MA. (1998). Alpatocopherol in CSF of subjects taking high dose vitamin E in the DATATOP study, Neurology.50 (6) 1900-1902. [PubMedabstract].Search for other works by this author on:OxfordAcademicPubMedGoogle $\quad$ Scholar.https://doi.org/10.1212/WNL.50.6.1900.

[31] Wheldon GH., Bhatt A., Keller P., and Hummler H. (1983). D, 1 alpha-Tocopheryl acetate (vitamin E): a long term toxicity and carcinogenicity study in rats. Int J VitamNutr Res, 53(3):287-96. [PubMed - abstract]. 